- edukativni članak -

\title{
AKUTNI APENDICITIS U TRUDNOĆI
}

\author{
Goran KALJEVIĆ, Nemanja PEJIĆ, Dušan MICIĆ, Branislav OLUJIĆ
}

Klinika za urgentnu hirurgiju, Centar za zbrinjavanje urgentnih stanja, Klinički centar Srbije, Beograd, Srbija

\section{Sažetak}

Akutni apendiciis je najčešće hirurško oboljenje u trudnoći. Na appendicitis treba posumnjati kada se trudna žena žali na novonastali bol u trbuhu. Ni jedna laboratorijska analiza nije se pokazala specifičnom za dijagnozu akutnog apendicitisa u trudnići. Značajan broj gubika fetusa dešava se naročito u prvom, a zatim u drugom trimestru trudnoće. Kombinacija simptoma i kliničkog pregleda pokazala se kao i dalje vitakna dijagnostika akutnog apendicitisa u trudnoći. Kontrakcije uterusa i difuzni ili paraumbilikalni bol koji migrira u desni donji kvadrant abdomena značajno je učestaliji symptom kod trudnica sa akutnim apendicitisom, nego sa drugom abdominalnom patologijom. Bol, mučnina, povraćanje, broj leukocita, CRP i aksilarna temperature nisu od naročitog značaja za dijagnostiku. Maternalni morbiditet i mortalitet nisu veći nego u ostaloj populaciji bolesnika sa akutnim apendicitisom, ali su komplikacije trudnoće značajno veće.

Ključne reči: trudnoća, akutni appendicitis, dijagnostika, komplikacije

\section{Uvod}

Neakušerske operacije u trudnoći imaju učestalost od 0,3-2,2\% [1]. Procenjeno je da približno 87.000 trudnica u USA i 115.000 trudnica u Evropskoj Uniji godišnje ima potrebu za nekom vrstom hirurške intervencije $u$ anesteziji koja nije vezana za porođaj. Novije studije pokazuju da je stvarna učestalost zapravo i veća jer su pokazale da je čak $0,35 \%$ žena koje su imale ambulantne intervencije, zatim 2,6\% žena koje su imale laparoskopske intervencije i $1,2 \%$ adolescentkinja imalo pozitivne rezultate testa trudnoće tokom priprema za operativni zahvat.

Ako anamnestički podaci pacijentkinje ukazuje na to da bi mogla biti trudna, poželjno je testirati je na trudnoću, mada to nije rutinska praksa. Hirurgija može biti neophodna u svakoj fazi trudnoće.

Studija koja je rađena u Švedskoj na 5.405 pacijentkinja koje su imale hirurški zahvat tokom trudnoće je pokazala da je
$42 \%$ imalo hirurški zahvat tokom prvog, $35 \%$ tokom drugog, a 23\% tokom trećeg trimestra trudnoće [2]. Laparoskopija zbog ginekoloških indikacija je najčešća procedura u prvom trimestru (34\%), dok je apendektomija najčešća procedura tokom drugog i trećeg trimestra. Indikacije mogu biti vezane za aktuelnu trudnoću, ili uopšte nisu povezane sa trudnoćom. Najčešće indikacije za operativne zahvate u trudnoći koje nisu vezane za aktuelnu trudnoću su akutna abdominalna stanja (najčešće apendicitis i holecistitis), trauma i maligniteti.

Kada je potrebno da se trudnica podvrgne neakušerskoj hirurgiji tokom trudnoće, anestezija mora biti podjednako bezbedna i za majku i za dete. Standardne anestetičke proce dure moraju biti modifikovane i prilagođene fiziološkim promenama u trudnoći i prisustvu fetusa.

Dve najnovije studije koje su istraživale smrtnost majki u Velikoj Britaniji ukazuju da je smrtnost majki prisutna 
i u ranoj trudnoći i da su najčešći uzroci krvarenje, sepsa, tromboembolijske komplikacije i anesteziološki razlozi [1].

Rizici koji se odnose na smrtnost fetusa su povezani sa:

1. efektima bolesti na fetus;

2. teratogenošću anestetičkih i ostalih lekova koji se primenjuju u perioperativnom periodu;

3. intraoperativnim poremećajima uteroplacentalne perfuzije i fetalne oksigenacije;

4. rizicima od prevremenog porođaja koji uvek postoje kod izvođenja neakušerskih intervencija tokom trudnoće $[1,2]$.

Tokom trudnoće dešavaju se bitne fiziološke promene kod majke, koje su rezultat povećane koncentracije hormona, mehaničkih promena usled porasta trudne materice, povećanih metaboličkih potreba majke, što sve može uticati na sniženje placentalnog protoka. Hormonske promene su verovatno odgovorne za većinu fizioloških promena koje se dešavaju u prvom trimestru trudnoće. Mehanički efekti postaju značajni kada materica izlazi iz karlice u drugoj polovini trudnoće.

\section{Akutni appendicitis u trudnoći}

Istraživanje o uticaju trudnoće na incidenciju apendektomije i apendicitisa je metodološki izazov.

Incidenca. Akutni apendicitis je najčešći neopstetrički uzrok akutnog abdomena u trudnoći. Javlja se u 1/5002000 trudnoća i obuhvata $25 \%$ operativnih indikacija za akutni abdomen u trudnoći (Mazze \& Kallen 1991) [3]. Čini se da je apendicitis češći u drugom tromesečju trudnoće, s incidencom od 35-50\%; međutim nema dokazanih podataka da trudnoća utiče na opštu učestalost apendicitisa. U kohortnoj studiji kojom je bilo obuhvaćeno preko 350.000 trudnica, pokazano je da je apendicitis $35 \%$ ređi antepartalno nego postpartalno [4].

Ne postoji ni jedan pouzdan znak ili simptom koji bi mogao pomoći u dijagnostikovanju apendicitisa $u$ trudnoći, a neki od klasičnih znakova nisu se pokazali od kliničke važnosti prilikom dijagnostikovanja akutnog apendicitisa u trudnoći. Konstantna bol u trbuhu je najčešći, a bol u donjem desnom kvadrantu prisutan je u 75$84 \%$ bolesnica i najpouzdaniji je simptom.

Razvoj apendicitisa tokom trudnoće češće je fulminantan nego u ostaloj populaciji iz brojnih razloga: povećana vaskularnost karlice i pomeranje apendiksa može ubrzati strangulaciju, a povećana lokalna limfna drenaža zajedno s ograničenom pokretljivošću omentuma zbog povećanja uterusa može pogodovati širenju upalnog procesa, te se kod perforacije češce odmah javljaju znaci difuznog peritonitisa, jer ograničena pokretljivost omentumu sprečava da ograniči process [1,5].

Dijagnostički postupak kod trudnice sa sumnjom na akutni appendicitis prikazan je u figure 1 .

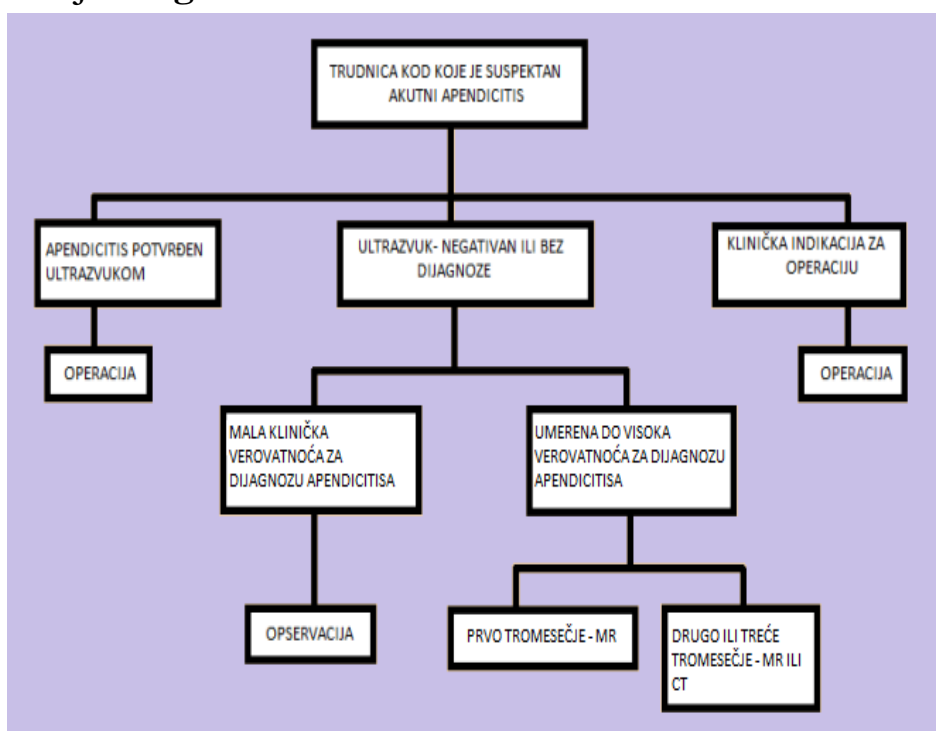

Figura 1. Dijagnostički postupak kod trudnice sa sumnjom na akutni appendicitis [6] 
Anamnestički podaci. Kako trudnoća napreduje, anamnestički podaci su sve manje specifični, Iako je bol dominantni simptom, nauzea, povraćanje, a naročito anoreksija i dijarea su sve češći simptomi akutnog apendicitisa [7].

Klinički pregled. Abdominalna masa može se propustiti fizikalnim pregledom zbog povećane gravidne materice. Osetljivost $\mathrm{u}$ desnom donjem kvadrantu na direktnu palpaciju je gotovo uvek prisutna. Rebound fenomen je prisutan kod 55-75\% bolesnica. Defans mišića postoji u 50-65 \% bolesnica; treba, međutim, imati u vidu da se kod odmakle trudnoće defans ređe sreće jer su mišići rastegnuti, a njihova neurološka rezerva nedovoljna da izazove mišićni spazam. Stoga je za ova dva znaka je verovatnije da će biti prisutni tokom prvog tromesečja nego kasnije u trudnoći, kada zbog oslabljenog tonusa trbušnog zida postaju teže uočljivi, što može dovesti do previđanja dijagnoze akutnog apendicitisa [8].

Psoas znak (Obraztsov znak) je bol prilikom pasivne ekstenzije desne natkolenice kada je inflamirani apendiks retrocekalno, odnosno retroperitonealno postavljen i angažuje m. psoas koji se ovim potezom izdužuje. Psoasov znak se ređe nalazi kod trudnica u poređenju sa negravidnim bolesnicama s apendicitisom.

Rektalna ili karlična osetljivost može se pojaviti u ranoj trudnoći, ali je netipična u kasnoj, s obzirom da se apendiks pomera iz svoje karlične lokacije obično ka gore [9], te manje od polovine bolesnica imalo rektalnu osetljivost prilikom digitorektalnog pregleda. Alderov znak se koristi za razlikovanje apendicitisa i tuboovarijske patologije kod bolova u donjem desnom kvadrantu tokom trudnoće i babinja. Razlika aksilarne i rektalne temperature od oko $1{ }^{\circ} \mathrm{C}$ ipak je evidentna u oko $70-75 \%$ pacijentkinja, osim kada postoje sistemske ko- mplikacije, obično zbog perforacije i sledstvenog peritonitisa. Inače, srednja maksimalna aksilarna temperatura za dokazani apendicitis je između $37,2-37,8^{\circ} \mathrm{C}$, ali može biti i viša od $39^{\circ} \mathrm{C}$ u slučajevima perforacije i difuznog peritonitisa [6]. Nažalost, samo 50\% trudnih bolesnica s akutnim apendicitisom imaju blagu temperaturu. Ova pojava povišene temperature se ne razlikuje od normalne trudničke populacije, a nalaz vredi i za tahikardiju pa oba znaka nisu sigurni, tako da je samo aksilarna temperatura netipičan znak [10].

U toku pregleda, potrebno je pronaći tačku najveće osetljivosti dok bolesnica leži, a zatim joj reći da se okrene na levi bok. Ukoliko se bol pomeri prema medijalno, postoji sumnja na tuboovarijalnu patologiju, mada je ovaj znak neisiguran. Očigledno je da ovaj znak može biti od koristi samo ako je materica dovoljno velika da se može palpirati. Aronov znak se odnosi na bol ili nelagodnost u prekordijalnoj ili epigastričnoj regiji dok se prime-njuje kontinuiran čvrst pritisak u području McBurneyjeve tačke. Arapov znak (kontraktura) je refleksna kontrakcija desnog zgloba kuka na bol kod apendicitisa.

U tumačenju laboratorijskih analiza treba imati u vidu da u trudnoći postoji fiziološka leukocitoza. CRP u trudnoći takođe je fiziološki nešto povišen, ali je bolji pokazatelj zapaljenskog procesa od broja leukocita [1,10]. Trudnice takođe često imaju pozitivan nalaz $u$ urinu, što ne sme zadovoljiti hirurga da tegobe proglasi cistitisom ili renalnom kolikom, patologijom takođe čestom u trudnoći. Ultrasonografija se u kliničkim studijama polazala dobrom metodom, za dijagnostiku apendicitisa. U drugoj polovini trudnoće radi se dok je pacijentkinja u levom dekubitalnom položaju. Studija (House JB et al.) je pokazala da je bilo 7\% lažno pozitivnih/negativnih dijagnoza, dok je u oko $82 \%$ slučajeva 
ultrasonografski postavljena sumnja na akutni apendicitis potvrđena intraoperativno [11]. U 11\% slučajeva nalaz ultrasonografije bio je inkonkluzivan.

Nakon sprovedenih dijagnostičkih postupaka u bolnici i potvrđene dijagnoze akutnog apendicitisa, lečenje je uvek hirurško uklanjanje apendiksa. Operacije se mogu izvesti laparotomski i laparoskopski. Sve izvađene biološke uzorke treba poslati na patohistološki pregled, jer se i u populaciji trudnih bolesnica može naći i druga patologija osim apendicitisa. Neke od potencijalnih prednosti laparoskopske apendektomije u trudnih bolesnica uključuju: smanjenu fetalnu depresiju zbog smanjenih zahteva za postoperativnim opioidima, manji rizik od komplikacija i smanjenu postoperativnu hipoventilaciju majke $[1,8]$. Ukupan mortalitet majki je manji od $1 \%$, kao i u ukupnoj populaciji. Redak je u prvom tromesečju, a povećava se $\mathrm{s}$ napredovanjem trudnoće, obično zbog previđanja dijagnoze i/ili odlaganja operacije više od $24 \mathrm{~h}$ po pojavi simptoma i sledstvene perforacije apendiksa [9].

Fetalni ishod. Danas je kombinovana stopa pobačaja i fetalnog mortaliteta vezana za akutni apendicitis u trudnoći u opadanju; kada apendiks nije perforirao, stopa je 0-5\%, a kod perforativnog apendicitisa, smrtnost fetusa raste do 20$36 \%$. Učinci bilo kakve medicinske intervencije na smrtnost fetusa moraju se uzeti u obzir u kontekstu određenog postojećeg pozadinskog rizika zajedničkog svim trudnoćama. To uključuje sledeće rizike: $3 \%$ za urođene mane, $15 \%$ za pobačaj, $4 \%$ za prema-turitet, $4 \%$ za zaostajanje u rastu i $1 \%$ rizika za mentalnu retardaciju ili neurološke smetnje u razvoju [10,11].

Apendicitis je najčešći hirurški uzrok gubitka fetusa tokom trudnoće zbog svoje učestalosti tokom trudnoće i česte atipične kliničke slike s odloženom dijagnozom i lečenjem.

Maternalni ishod. Ukupan mortalitet majki je manji od 1\%, kao i u ukupnoj populaciji. Redak je u prvom tromesečju, a povećava se $\mathrm{s}$ napredovanjem trudnoće, obično zbog previđanja dijagnoze i/ili odlaganja operacije više od 24 sata po pojavi simptoma i sledstvene perforacije apendiksa [4-6]. Odlaganjem operacije više od $24 \mathrm{~h}$ po početku simptoma značajno povećava stopu perforacije i morbiditeta stanja majke, a naročito fetalnog ishoda. Ako je prisutna perforacija apendiksa, smrtnost majki se javlja kod 4\% bolesnica za razliku od manje od $1 \%$ u neperforiranog apendicitisa. Rizik za perforaciju se povećava sa gestacijskim dobom, a perforacija u trećem tromesečju često rezultuje prevremenim porođajem. Rizik prevremenog porođaja je najveći tokom prve nedelje nakon operacije.

Laparoskopske tehnike uključuju smanjenu hiruršku traumu, manju manipulaciju gravidnim uterusom, raniji oporavak funkcije creva, kraće vreme do oralnog unosa, kraću postoperativnu dužinu boravka u bolnici i brži povratak na posao.

\section{Literatura}

1. Committee on Obstetric Practice American Society of Anesthesiologists. Committee Opinion No. 696: Nonobstetric Surgery During Pregnancy. Obstet Gynecol. 2017 Apr; 129(4):777-78. doi: 10.1097/AOG.0000000000002014.

2. Practice Guidelines for Obstetric Anesthesia: Management of the pregnant patient undergoing nonobstetric surgery. An Updated Report by the American Society of Anesthesiologists Task Force on Obstetric Anesthesia and the Society for Obstetric Anesthesia and Perinatology. Anesthesiology. 2016; 124(2):270-300. DOI: 10.1097/ALN.0000000000000935. 
3. Mazze RI, Kallen B. Appendectomy during pregnancy: a Swedish registry study of 778 cases. Obstet Gynecol. 1991 Jun; 77:835-40.

4. Bickell NA, Aufses AH Jr, Rojas M, Bodian C. How time affects the risk of rupture in appendicitis. J Am Coll Surg. 2006 Mar; 202(3):401-03.

5. Mourad J, Elliott JP, Erickson L, Lisboa L. Appendicitis in pregnancy: new information that contradicts long-held clinical beliefs. Am J Obstet Gynecol. 2000 May;182(5):1027-29.

6. Kolačević M. Akutni appendicitis u trudnoći (diplomski rad). Medicinski fakultet Sveučilišta u Zagrebu, Klinika za kirurgiju KBC-a Zagreb, Zagreb, 2014.

7. Andersson RE, Lambe M. Incidence of appendicitis during pregnancy. Int $J$ Epidemiol. 2001 Dec; 30(6):1281-85.

8. Zingone F, Sultan AA, Humes DJ, West

J. Risk of acute appendicitis in and around

Korespodencija:

Goran Kaljević

Klinički centar Srbije

Pasterova 2

11000 Beograd

Srbija

Tel.: +381 11 366-2018

E-mail: mediacentar@kcs.ac.rs pregnancy: a population-based cohort study from England. Ann Surg. 2015 Feb;261(2):332-37. doi: 10.1097/ SLA.0000000000000780.

9. Lee SL, Walsh AJ, Ho HS. Computed tomography and ultrasonography do not improve and may delay the diagnosis and treatment of acute appendicitis. Arch Surg. 2001 May;136(5):556-62.

10. Oto A, Srinivasan PN, Ernst RD, Koroglu M, Cesani F, Nishino $\mathrm{T}$, et al. Revisiting MRI for appendix location during pregnancy. AJR Am J Roentgenol. 2006; 186: 883-87. Doi: 10.2214/ AJR.05.0270

11. House JB, Bourne CL, Seymour HM, Brewer KL. Location of the appendix in the gravid patient. J Emerg Med. 2014 May;46(5):741-44. doi: 10.1016/ j.jemermed.2013.09.033.

Rad primljen: 08.01.2019.

Prihvaćen: 15.03.2019. 
- education article -

\title{
ACUTE APPENDICITIS DURING PREGNANCY
}

Goran KALJEVIĆ, Nemanja PEJIĆ, Dušan MICIĆ, Branislav OLUJIĆ

Emergency Surgery Clinic, Center for Emergency Medical Care, Clinical Centre of Serbia, Belgrade, Serbia

\begin{abstract}
Acute appendicitis is the most common surgical emergency during pregnancy. It should be suspected when a pregnant woman complains of newly developed abdominal pain. No laboratory finding was found to be conclusive for acute appendicitis during pregnancy. A considerable percentage of fetal loss occurs after appendectomy in pregnant women during the first trimester, but also during the second. The combination of symptoms and clinical findings are crucial in making the diagnosis of acute appendicitis during pregnancy. Uterine contractions and diffuse or periumbilical abdominal pain, which migrates into the right lower quadrant are significantly more frequent among pregnant women with acute appendicitis than in pregnant women with other types of abdominal pathology. Abdominal pain, nausea, vomiting, leukocyte count, CRP and body temperature were of no help in establishing the correct diagnosis. The maternal morbidity and mortality were no higher than they were in other, non-pregnant individuals with acute appendicitis. However, the complications of the pregnancy itself were found to be significant.
\end{abstract}

Key words: pregnancy, acute appendicitis, diagnostic procedures, complication 